\title{
PERCEPÇÃO DA ENFERMAGEM SOBRE REINTERNAÇÕES E ALTA HOSPITALAR DE IDOSOS: RESULTADOS PRELIMINARES DA ANÁLISE DE CONTEÚDO*
}

\author{
Maria Manuela Rino Mendes** \\ Márcia Regina Martins Alvarenga***
}

\section{INTRODUÇÃO}

O aumento da expectativa de vida, expressa além do envelhecimento, o acréscimo nos índices das doenças crônico-degenerativas que acometem, predominantemente, a população adulta e em particular a idosa com 60 anos e mais (LESSA,1998).

CASELLI (1998), ao caracterizar a morbidade hospitalar do idoso em São Carlos/SP, demonstrou que 4.125 internações foram geradas por 2.829 idosos num ano, representando a média de 1,5 internação por paciente. A ocorrência das hospitalizações tem sido um marcador de qualidade hospitalar e o seu aumento onera o sistema de saúde.

\section{OBJETIVO}

Descrever a percepção dos elementos da equipe de enfermagem quanto às reinternações de idosos e na organização da alta hospitalar.

\section{METODOLOGIA}

Este estudo foi desenvolvido num hospital geral de médio porte, em Marília/SP, sendo a população alvo os catorze funcionários da enfermagem, do período diurno (uma enfermeira, onze auxiliares e dois atendentes de enfermagem).

A coleta de dados foi realizada através de entrevistas gravadas, orientadas pelas questões abaixo, sendo transcritas e submetidas a "análise de conteúdo" (BARDIN, 1977).

- Na sua opinião, quais fatores contribuem para as reinternações de idosos na instituição ?

- Como é planejada a alta hospitalar do idoso? Destaque as atividades da equipe à alta.

- É feito algum acompanhamento do idoso após a alta hospitalar? Em caso afirmativo, detalhe-o e as relações com os serviços de saúde.

\section{DESCREVENDO A PERCEPÇÃO DOS ELEMENTOS DA EQUIPE DE ENFERMAGEM}

Indagando a equipe, sobre os fatores que poderiam contribuir para as reinternações dos idosos, predominaram as alegações de natureza social e econômica da família, a exemplo: "Pobreza" (Aux.11); "...na família ninguém cuida porque todo mundo trabalha fora" (Aux.7).

Para SILVA (1996), a família desempenha um importante papel no apoio aos idosos, porém, este pode estar comprometido quando há dificuldade de acesso ou inexistência de rede de recursos sociais, pois, os idosos fragilizados impõem a seus cuidadores familiares novos papéis, sobrecarga psicológica e física, além do ônus financeiro.

Quanto ao planejamento da alta hospitalar, as referências expressas pelos entrevistados fazem alusão à rotina centrada na decisão médica, informando a condição melhorada do cliente para alta, como também, as ações esperadas da equipe de enfermagem para

* Parte da pesquisa desenvolvida no mestrado - área Enfermagem Fundamental - Escola de Enfermagem de Ribeirão Preto da Universidade de São Paulo

** Professor Doutor do Departamento de Enfermagem Geral e Especializada da Escola de Enfermagem de Ribeirão Preto da Universidade de São Paulo. (Orientadora)

*** Aluna do Programa de Mestrado da área de Enfermagem Fundamental da Escola de Enfermagem de Ribeirão Preto da Universidade de São Paulo 
viabilizar a comunicação à família e saída administrativa da instituição. Os recortes das falas ilustram essa percepção: "Não tem protocolo de alta" (Enf.); "O médico comunica a alta, ...entramos em contato com a família, ...explico a receita,... se for acamado, dou dicas de como lidar com ele..." (Aux.3).

Alguns depoimentos da enfermagem expressaram outras iniciativas, detalhando os cuidados a serem dispensados pela família com o idoso, no domicílio e procura por serviços de saúde, quando necessário.

MARRA et al. (1989), entendem que o plano de alta deve ser elaborado pelo enfermeiro com a participação dos profissionais que atuam diretamente com o idoso, de modo a destacar os diversos aspectos de vigilância e cuidado da família após a alta.

O acompanhamento do cuidado familiar do idoso, com a saída do hospital, não é destacado como responsabilidade da instituição. Alguns funcionários ressaltam a importância do retorno aos serviços de saúde ou ambulatório da instituição (acompanhamento ou intercorrências). Apesar das orientações, na realidade

\section{REFERÊNCIAS BIBLIOGRÁFICAS}

01. BARDIN, L. Análise de conteúdo. Lisboa, Edições 70, 1977.

02. CARMAGNANI, O.S. (org.) Planejamento do programa da saúde do idoso. Araraquara. Centro Regional de Reabilitação, 1995 81p.

03. CASELLI, M.P. A morbidade hospitalar do idoso no município de São Carlos/SP - em 1996. São Paulo, 1998. 136p. Dissertação (Mestrado) - Faculdade de Saúde Pública, Universidade de São Paulo. os serviços públicos de saúde estão desarticulados, conforme a expressão "Orientamos para procurar o posto de saúde, mas nem sempre ele procura e acaba retornando ao hospital" (Aux.01).

CARMAGNANI (1995) revela a existência de recursos para reabilitação e recuperação da saúde, de natureza médica, educacional e apoio aos enfermos e incapacitados, porém, a divulgação e o acesso ao sistema de saúde são precários, refletindo um serviço de baixa qualidade à população.

A análise dos depoimentos revela o desconhecimento da equipe de saúde sobre a complexidade das condições dos idosos que não responde ao modelo clínico tradicional focalizado apenas na doença, pois a natureza social é predominante e exige ações intersetoriais. E ainda, a organização elementar da alta hospitalar aponta para a necessidade de sistematizar o trabalho da equipe de enfermagem com os demais segmentos da saúde, de modo a identificar as razões das reinternações de idosos e intervir nesse processo.

04. LESSA, I. O adulto brasileiro e as doenças da modernidade: epidemiologia das doenças crônicas não-transmissíveis. São Paulo: Hucitec/ Abrasco, 1998. 284p.

05. MARRA, C. C.; CARMAGNANI, M.I.S.; AFONSO, C.; SALVADOR, M.E. Orientação planejada de enfermagem na alta hospitalar. Acta Paulista Enfermagem, v. 2, n. 4, p. 12327, dez. 1989.

06. SILVA, E.B.N. A relação familiar e o idoso. Gerontologia, v. 4, n. 2, p. 75-78, 1996. 